\title{
An Analysis of Public Conflict Research Trends in Korea Using Social Network Analysis
}

\author{
Na-Rang Kim ${ }^{1}$, Soon-Goo Hong ${ }^{2, *}$ and Seong Bae Lim $^{3}$ \\ ${ }^{12}$ Department of Management Information Systems, Dong-A University, \\ Gudukro 225, Seo-Gu, Busan, 602-706, South Korea \\ ${ }^{3}$ Department of Management Information Systems, St. Mary's University, \\ One Camino Santa Maria San Antonio, TX, USA, 78228 \\ ${ }^{1}$ whitecoral@hanmail.net, ${ }^{2}$ shong@dau.ac.kr, ${ }^{3}$ seongblim@gmail.com
}

\begin{abstract}
The purpose of this study is to analyze the trend of public conflict research in Korea since 2000 using a social network analysis. The subjects of this study were theses on public conflict. After extracting keywords from 80 theses in the RISS, degree centrality, betweenness centrality, and closeness centrality were analyzed using the social network analysis method. The results showed that the conspicuous research topics were conflict management and governance to solve public conflicts, and public policy tended to be researched alongside other keywords. The most researched subject was unwelcomed facilities, which implies that in most cases, conflicts occurred and developed due to the resistance of residents to the policy promotion and the location selection of unwelcomed facilities. Furthermore, studies on unwelcomed facilities showed strong connectivity with such keywords as environment, trust, and communication, which suggests that many studies have been conducted to solve conflicts. This study will contribute to the understanding and activation of public conflict research by presenting the future development directions for public conflict research in Korea.
\end{abstract}

Keywords: SNA (social network analysis), research trends, public conflict, degree centrality, closeness centrality, betweenness centrality

\section{Introduction}

Public conflict means a conflict that has been caused by values, objectives, or means that are incompatible among interested parties in the process of public policy or legislation promoted by central or local governments, which have resulted in serious socioeconomic consequences and required government intervention or involvement (Lim, 2010). Public conflicts are characterized by a large number of interested parties, complex interconnections between conflicting issues, and a challenge of identifying alternatives or solutions that are satisfactory to all the interested parties (Ha, 2007).

Public conflict is a field that is considered important by the government; therefore, it has been researched continuously in various disciplines in regards to the policy basis. However, it is difficult to determine how many studies are currently being conducted and in which specific directions.

Recently, social network analysis (SNA) has been used as a new research method to improve the limitations of previous research methods for research trends (Wasserman \& Faust, 1994). SNA visualizes the structure of a network based on various connected data to understand how the data are connected to each other by finding nodes at important positions (Lee, 2013). Studies analyzing the research trends using SNA include a study

Received (January 22, 2018), Review Result (March 7, 2018), Accepted (March 15, 2018)

${ }^{*}$ Corresponding Author 
that analyzed the research trends for the domestic and international education of gifted children (Yoon et al., 2016) and a study on the research trends for career education in the field of science education (Shin, 2017). The present study aims to present a better direction for the development of public conflict research by comparing and analyzing the status of public conflict research since 2000 using SNA in order to discuss the implications of the findings.

\section{Research Methods and Analysis}

The core concepts of SNA include degree, density, degree centrality, closeness centrality, betweenness centrality, and any structural holes. Degree refers to the number of other nodes to which a node is connected. Density is the ratio of actual relations to the total possible relations. Density is generally inversely proportional to the size of a group.

The representative centralities used as a result of SNA are degree centrality, closeness centrality, and betweenness centrality. Degree centrality, which indicates the number of connected nodes, is a good measure of local centrality. Closeness centrality is a centrality measure that considers directly and indirectly connected relations where a theme keyword appears with other theme keywords together in a thesis (Lee, 2006). Due to the nature of closeness centrality, a theme keyword with a high closeness centrality has a high influence on the total knowledge map. Betweenness centrality is a centrality measure that indicates how much a theme keyword acts as a 'bridge' between two specific theme keywords that are not directly interlinked. A theme keyword with a high betweenness centrality can have the effect of linking theme keywords that have not been used together in previous studies. Therefore, when searching for new research areas or topics for interdisciplinary or convergent research, it may be effective to focus on the theme keywords with a high betweenness centrality (Park et al., 2016).

\subsection{Subjects of Study}

In this study, three researchers selected 80 theses by searching the theses published in academic research information services since 2000. The numbers of theses on public conflict by year are as follows.

Table 1. Annual Number of Theses

\begin{tabular}{|c|c|c|c|c|c|c|c|c|c|c|c|c|}
\hline Year & 2006 & 2007 & 2008 & 2009 & 2010 & 2011 & 2012 & 2013 & 2014 & 2015 & 2016 & 2017 \\
\hline $\begin{array}{c}\text { Number } \\
\text { of } \\
\text { theses }\end{array}$ & 1 & 5 & 8 & 7 & 3 & 10 & 10 & 7 & 6 & 7 & 8 & 8 \\
\hline
\end{tabular}

As a result of searching theses published since 2000, it was found that the first thesis on public conflict was published by Doo-Hwan Kim in 2006, who investigated the factors influencing the resolution of public policy conflicts. In particular, many theses were published in 2011 and 2012. The most preferred research method of theses on public conflict was case study during this time period. Some theses used a mixture of case study and empirical research or an empirical research method based on surveys and existing data. 
Table 2. Research Methods

\begin{tabular}{|l|c|}
\hline \multicolumn{1}{|c|}{ Research Method } & Number of Cases \\
\hline Case studies & 62 \\
\hline Combination of case and empirical studies & 7 \\
\hline Empirical studies & 5 \\
\hline Q-methodology & 2 \\
\hline Cross-tabulation analysis & 1 \\
\hline Network analysis & 1 \\
\hline Simulation & 1 \\
\hline Frame analysis & 1 \\
\hline Total & 80 \\
\hline
\end{tabular}

The subjects of public conflict research are an important issue in a case study and are largely divided into unwelcomed facilities and welcomed facilities as well as development and redevelopment. In particular, unwelcomed facilities was the most studied subject in public conflict research. This means that in most cases, conflicts occurred and developed due to the resistance of residents to a policy promotion and the site selection of unwelcomed facilities.

Table 3. Objects of Conflict

\begin{tabular}{|c|c|}
\hline Object of conflict & Number of theses \\
\hline Non-preferred facilities & 47 \\
\hline Preferred facilities & 5 \\
\hline Development & 4 \\
\hline Redevelopment & 13 \\
\hline
\end{tabular}

The keywords, which are specified in the thesis by the authors to identify the main themes of their theses, were used as raw data. We analyzed the degree centrality, closeness centrality, and betweenness centrality using NetMiner4.2 to understand the roles and knowledge structure inherent in the theme keywords.

\subsection{Social Network Analysis}

The keywords specified in theses by authors to identify their main themes were used as raw data. The analysis of collected data was divided into preprocessing, network creation, analysis, and diagramming of the steps. The weight indicating the degree of connectivity between nodes in the SNA is a relative weight. This means that the higher the weight and the higher the frequency of simultaneous appearance, the higher the connectivity is between the keywords. As shown in Table 1, military facilities, governance, unwelcomed facilities, and negotiation all demonstrated a high value of connectivity with conflict management, and unwelcomed facilities had a high value of connectivity with location. 
Table 4. Weight Higher Order of the Keywords used in Public Conflict since 2000

\begin{tabular}{|c|c|c|c|}
\hline & node1 & node2 & Weight \\
\hline 1 & $\begin{array}{c}\text { Conflict } \\
\text { management }\end{array}$ & Military facilities & 5 \\
\hline 2 & Military facilities & Conflict management & 5 \\
\hline 3 & $\begin{array}{c}\text { Conflict } \\
\text { management }\end{array}$ & Governance & 4 \\
\hline 4 & $\begin{array}{c}\text { Conflict } \\
\text { management }\end{array}$ & Unwelcomed facilities & 4 \\
\hline 5 & $\begin{array}{c}\text { Conflict } \\
\text { management }\end{array}$ & Negotiation & 4 \\
\hline 6 & Governance & Conflict management & 4 \\
\hline 7 & $\begin{array}{l}\text { Unwelcomed } \\
\text { facilities }\end{array}$ & Conflict management & 4 \\
\hline 8 & $\begin{array}{l}\text { Unwelcomed } \\
\text { facilities }\end{array}$ & Location & 4 \\
\hline 9 & Location & Unwelcomed facilities & 4 \\
\hline 10 & Negotiation & Conflict management & 4 \\
\hline
\end{tabular}

Degree centrality, closeness centrality, and betweenness centrality were analyzed using the SNA in order to investigate the roles and knowledge structure inherent in the theme keywords.

\subsubsection{Degree Centrality Analysis}

In the SNA, degree centrality indicates how much the theme keywords related to other theme keywords. Degree centrality is a measure of the degree to which a node is located at the center of a network. The larger the value, the more intertwined with other nodes and the more central role that the keyword plays in the network. A keyword with a high degree centrality is used frequently in conjunction with other keywords in the thesis, and this means that the keyword is used frequently as a research theme (Ko et al., 2013). Degree centrality analysis showed that conflict management had the highest degree centrality and was at the center. Besides that, environment, conflict factors, governance, trust, and unwelcomed facilities also appeared. Figure 1 shows the results of the degree centrality analysis of the theme keywords. 


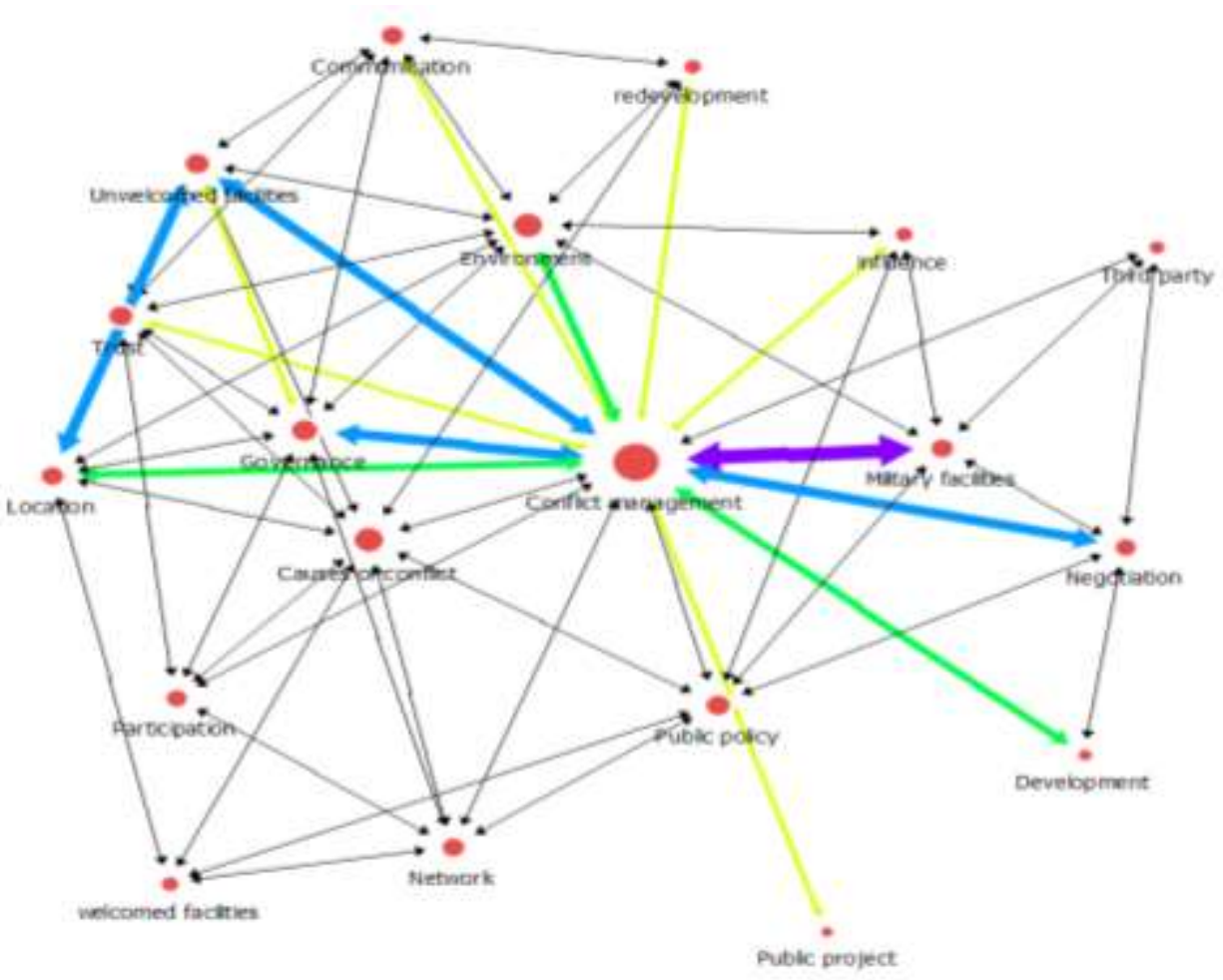

Figure 1. Degree Centrality of Theme Keywords in the Field of Public Conflict since 2000

Table 4. Degree Centrality of Theme Keywords in the Field of Public Conflict since 2000

\begin{tabular}{|l|l|l|}
\hline & In-Degree Centrality & Out-Degree Centrality \\
\hline Conflict management & 0.944444 & 0.944444 \\
\hline Environment & 0.5 & 0.5 \\
\hline Causes of conflict & 0.5 & 0.5 \\
\hline Governance & 0.444444 & 0.444444 \\
\hline Trust & 0.388889 & 0.388889 \\
\hline Unwelcomed facilities & 0.388889 & 0.388889 \\
\hline Public policy & 0.388889 & 0.388889 \\
\hline Location & 0.333333 & 0.333333 \\
\hline Communication & 0.333333 & 0.333333 \\
\hline Network & 0.333333 & 0.333333 \\
\hline Military facilities & 0.333333 & 0.333333 \\
\hline Negotiation & 0.277778 & 0.277778 \\
\hline Participation & 0.277778 & 0.277778 \\
\hline Urban development & 0.222222 & 0.222222 \\
\hline influence & 0.222222 & 0.222222 \\
\hline welcomed facilities & 0.222222 & 0.222222 \\
\hline Third party & 0.166667 & 0.166667 \\
\hline Development & 0.11111 & 0.111111 \\
\hline Public project & 0.055556 & 0.055556 \\
\hline & & \\
\hline
\end{tabular}




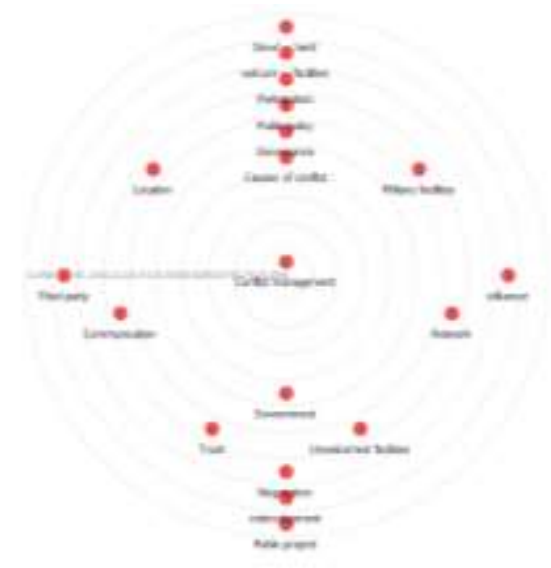

Figure 2. Degree Centrality Concentric Map of Theme Keywords in the Field of Public Conflict since 2000

\subsubsection{Betweenness Centrality Analysis}

Betweenness centrality, a concept proposed by Freeman (1977), is a measure of the position of a node between other nodes in a network. The betweenness centrality is high if a node is located on the shortest path between various nodes or if it connects different groups. In the network of keywords related to public conflict, conflict management had the highest betweenness centrality. In general, degree centrality is proportional to the betweenness centrality to some degree, but the nodes that show a difference between degree centrality and betweenness centrality are likely to play a special role in the network. In the present study, public policy showed a distinct difference between degree centrality and betweenness centrality. Because betweenness centrality indicates how conspicuous the network bridge's role is, if a specific theme keyword is more open to other theme keywords, its betweenness centrality can be greater than the degree centrality. In other words, a public policy whose betweenness centrality is greater than degree centrality means that it is being studied in conjunction with other theme keywords.

\section{Table 5. Betweenness Centrality of Theme Keywords in the Field of Public} Conflict since 2000

\begin{tabular}{|l|c|}
\hline & Node Betweenness Centrality \\
\hline Conflict management & 0.462834 \\
\hline Causes of conflict & 0.064359 \\
\hline Public policy & 0.051139 \\
\hline Environment & 0.050376 \\
\hline Governance & 0.024282 \\
\hline Location & 0.02351 \\
\hline Network & 0.019925 \\
\hline Millitary facilities & 0.017429 \\
\hline Negotiation & 0.014379 \\
\hline Trust & 0.010616 \\
\hline Unwelcomed facilities & 0.00816 \\
\hline Communication & 0.005447 \\
\hline Welcomed facilities & 0.003813 \\
\hline Redevelopment & 0.003535 \\
\hline Participation & 0.002723 \\
\hline Influence & 0.002179 \\
\hline
\end{tabular}




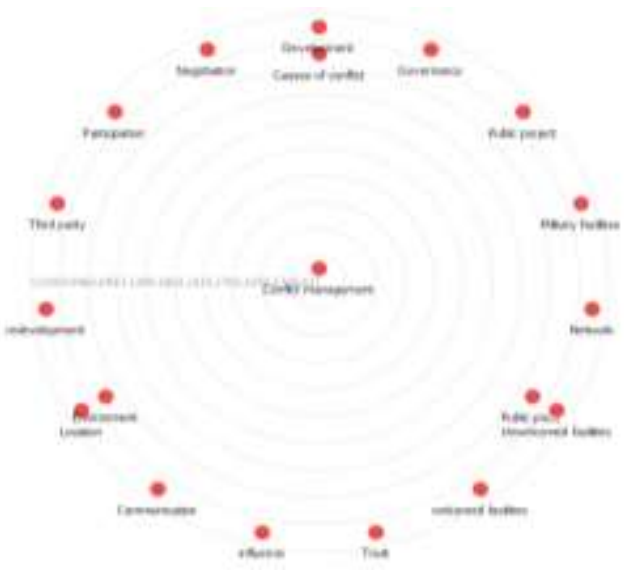

Figure 3. Betweenness Centrality Concentric Map of Theme Keywords in the Field of Public Conflict since 2000

\subsubsection{Closeness Centrality Analysis}

Closeness centrality indicates how close a node is to the center in a network. It is a representative measure of the overall centrality of a node and can be measured by the closeness or distance to other nodes. A node with the smallest sum, which would result from the shortest distances, is obviously the node at the center. The closeness centrality analysis can determine which keyword has the largest general impact across the network. The keyword with the highest closeness centrality is located at the shortest distance from all other keywords and can be regarded as a keyword having a high degree of influence. The analysis results showed that conflict management was the keyword with the highest closeness centrality. Besides that, environment, conflict factor, governance, and trust all showed high closeness centralities. In other words, these keywords were closest to the other nodes in the network.

\section{Table 5. Closeness Centrality of Theme Keywords in the Field of Public} Conflict since 2000

\begin{tabular}{|l|ll|}
\hline & \multicolumn{1}{|c|}{ In-Closeness } & \multicolumn{1}{c|}{ Out-Closeness } \\
\hline Conflict management & 0.947368 & 0.947368 \\
\hline Environment & 0.666667 & 0.666667 \\
\hline Causes of conflict & 0.666667 & 0.666667 \\
\hline Governance & 0.642857 & 0.642857 \\
\hline Trust & 0.62069 & 0.62069 \\
\hline Unwelcomed facilities & 0.62069 & 0.62069 \\
\hline Public policy & 0.62069 & 0.62069 \\
\hline Location & 0.6 & 0.6 \\
\hline Network & 0.6 & 0.6 \\
\hline Military facilities & 0.6 & 0.6 \\
\hline Negotiation & 0.580645 & 0.580645 \\
\hline Participation & 0.580645 & 0.580645 \\
\hline Communication & 0.580645 & 0.580645 \\
\hline Redevelopment & 0.5625 & 0.5625 \\
\hline Influence & 0.5625 & 0.5625 \\
\hline Third party & 0.529412 & 0.529412 \\
\hline Development & 0.514286 & 0.514286 \\
\hline Welcomed facilities & 0.5 & 0.5 \\
\hline Public project & 0.5 & 0.5 \\
\hline
\end{tabular}




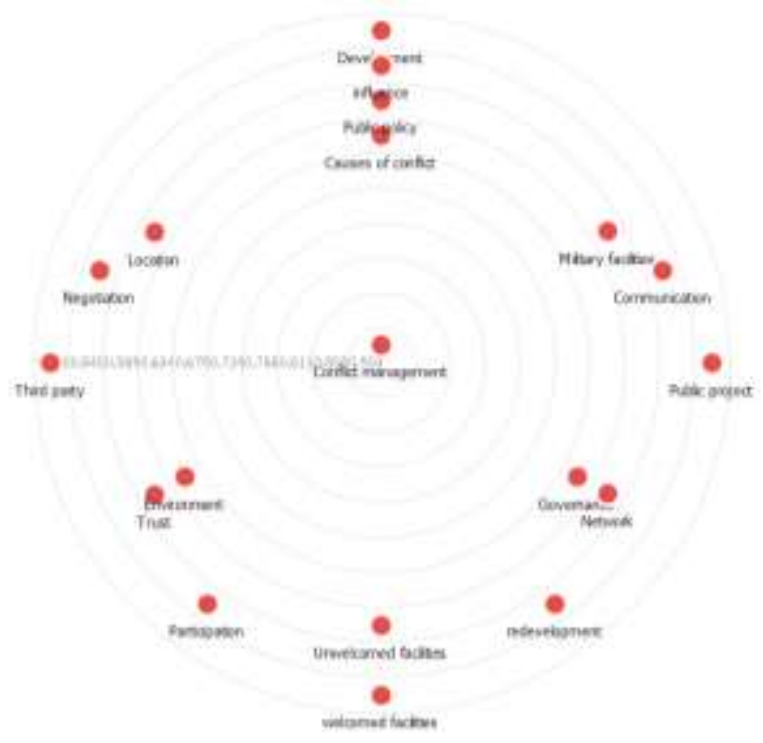

Figure 4. Closeness Centrality Concentric Map of Theme Keywords in the Field of Public Conflict since 2000

\section{Conclusion}

The purpose of this study is to examine the flow of knowledge structure and knowledge mapping in the field of public conflict since 2000. The results of the study are as follows. For the research methods of public conflict, 62 of the 80 theses used the case study method. They investigated specific cases and suggested solutions for conflict management based on those cases. On the other hand, quantitative research to secure objectivity according to the characteristics of common cases were also conducted occasionally.

The subjects of the public conflict research in the 80 theses were unwelcomed facilities and redevelopment cases based on the order of frequency. This result suggests that there are many public conflicts that result from unwelcomed facilities, such as radioactive waste sites, nuclear power plants, the Miryang Transmission Tower, the Jeju naval facility, and thermal power plants.

The top keywords were conflict management and governance to resolve public conflicts. Keywords related to the conflict factors used to understand the nature of conflict also appeared. In addition, as there were many case studies, the keywords corresponding to the types of cases, such as location, environment, development, and redevelopment, were also used in combination. Meanwhile, public policy demonstrated a low degree centrality but a high betweenness centrality. This suggests that public policy is researched in conjunction with other keywords because betweenness centrality is a measure of how conspicuous the bridge role of a node is within a network. In other words, public policy is being researched in combination with a wide range of fields that goes beyond the research scope of public policy.

The limitations of this study and suggestions for future research are as follows. First, there are many theses on a single case of public conflict. Therefore, in order to achieve objectivity, quantitative studies using various research methods, such as multi-case comparative research and empirical research, are needed. Second, many studies focused on redevelopment and development and the location of unwelcomed facilities, such as nuclear power plants and radioactive waste sites, which are developed through government policy. Therefore, in order to solve complex and diverse public problems, conflict cases in various fields should be considered as research subjects. 
As a trend analysis study centered on theses only, this study may have limitations in regards to public conflict research. Thus, future studies should use various forms of research materials to provide additional data for public conflict research.

\section{Acknowledgments}

This work was supported by the Ministry of Education of the Republic of Korea and the National Research Foundation of Korea (NRF-2015S1A3A2046781).

"This paper is a revised and expanded version of a paper entitled An Analysis of Domestic Research Trends on Public Conflict Using Social Network Analysis presented at AST 2018, Ho Chi Minh, Vietnam , February 1st".

\section{References}

[1] D. H. Kim, "A Comprehensive Framework of Conflict-Resolution-Factors", Space and society, vol. 26, (2006), pp. 88-119.

[2] D. J. Lim, "A Study on the Actual Condition of Public Dispute Management in the Central Government and Effective Management of Conflict Management", KIPA Research Report, (2010).

[3] L. C. Freeman, "A Set of Measures of Centrality based on Betweenness", Sociometry, vol. 40, no. 1, (1977), pp. 35-41.

[4] H. Y. Ha, "Analysis on Critical Factors of Conflict Resolution in Public Sectors: Focused on the Effect of Major Factors in the Conflict Management", Korean Government Scholarship, vol. 41, no. 3, (2007), pp. 273-296.

[5] J. A. Yoon and H. A. Seo, "Research Trends in Science Gifted Education from 2011 to 2015: Literature Analysis vs Social Network Analysis", Science Education Research, vol. 40, no. 3, (2016), pp. 267-286.

[6] J. C. Ko, G. T. Cho and W. H. Cho, "Recent Research Trends of Technology Management through Keyword Network Analysis", Korea Intelligent Information Systems Society 2013 Spring Conference, (2013), pp. 57-65.

[7] J. Y. Lee, "Centrality Measures for Bibliometric Network Analysis", Journal of Korea Literature and Information Science, vol. 40, no. 3, (2006), pp. 191-214.

[8] S. J. Park, J. W. Lee and H. W. Lee, "Building knowledge map based on social network analysis of sports psychology topic area keyword”, Journal of Korean Physical Education, vol. 55, no. 3, (2016), pp. 187-198

[9] S. I. Shin, M. S. Ha and J. K. Lee, "Research Trends on Career Education in the Science Education Field from the Perspective of Social Network Analysis: Focusing on Domestic Journals", Learner-centered curriculum education research, vol. 17, no. 6, (2017), pp. 293-312.

[10] S. S. Lee, "Network analysis methods", Nonhyeong Publisher, vol. 39, no. 41, (2012), pp. 177-178.

[11] Stanley. Wasserman, Katherine. Faust, "Social Network Analysis: Methods and Applications. Cambridge", Cambridge University Press, (1994).

\section{Authors}

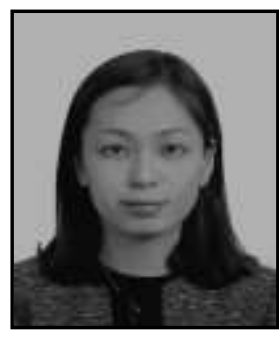

Na-Rang Kim is a Researcher at Dong-A University, Korea. She is currently working for regional innovation by utilizing IT, Design Thinking and Co-creation.

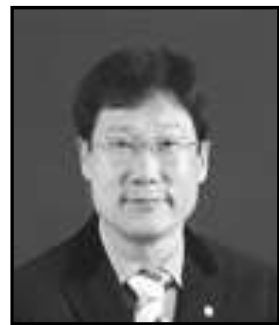

Soon-Goo Hong is a Professor in the department of Management Information Systems at Dong-A University, Korea. He holds a Ph.D. in management from the University of Nebraska-Lincoln. $\mathrm{He}$ is currently working for regional innovation by utilizing IT and Co-creation. He serves as a chair of the IT and Co-creation based Regional Innovation Research Group. 


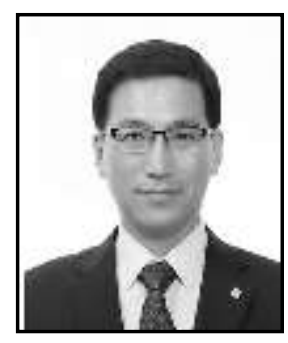

Seongbae Lim is a chair and professor of department of finance and quantitative management at St' Mary's University in San Antonio, Texas. Dr. Lim graduated from the University of Nebraska Lincoln with information systems management major. He used to worked for State University of New York, and worked for St. Mary' University for last 10 years. His recent research topics include co-creation, convergence, blockchain driven governance. and living innovation (a new innovation paradigm for the future). 